\title{
DIMENSIONES SEMÁNTICAS DE LA FELICIDAD
}

\section{JORGE MARTÍNEZ}

Instituto de Filosofía.

Proyecto de Investigación Interdisciplina 3/2014: "La felicidad como derecho".

Vicerrectoría de Investigación.

Pontificia Universidad Católica de Chile.

jorge.martinezbarrera6@gmail.com

DOI: http://doi.org/10.29035/ucmaule.53.115

\section{RESUMEN}

La reflexión acerca de la felicidad humana ha conocido últimamente una notable revigorización. Aun cuando este asunto ha sido transversal en toda la historia de la filosofía, ahora parece haber sido descubierto en otros ámbitos, tanto políticos como en el sentido de expectativas personales. Este trabajo se propone, atendido este contexto contemporáneo, repensar la felicidad incorporando la noción clásica, que encuentra en Aristóteles a su más relevante expositor en la antigüedad. Para ello se comenzará con una referencia a la idea más habitual de la felicidad, esto es, el estado anímico de bienestar y el modo como ella es adoptada, incluso a nivel político. Desde ahí, examinaremos la concepción aristotélica, sus implicancias y una importante corrección estoica. La importancia de la referencia a Aristóteles está dada por su noción de que la felicidad no es en lo esencial un Páthos sino una Praxis. Una vez despejado el carácter práctico de la felicidad, que no excluye la Praxis contemplativa, haremos referencia a la posibilidad de articular este concepto con la felicidad en sede cristiana.

Palabras clave: Felicidad, Aristóteles, Páthos, Praxis, Teleología. 


\section{ABSTRACT}

Reflection on human happiness has recently seen a remarkable reinvigoration. Although this issue has been transversal throughout the history of philosophy, now it seems to have been discovered in other areas, both political and in the sense of personal expectations. This work intends, given this contemporary context, to rethink happiness by incorporating the classical notion, which finds in Aristotle its most important expositor in antiquity. This article begins with a reference to the most common idea of happiness, that is, the state of mind of well-being and how it is adopted even at the political level. From there we will examine the Aristotelian conception, its implications and an important Stoic correction. The importance of the reference to Aristotle is given by his notion that happiness is not essentially a páthos but a praxis. Once the practical nature of happiness is clarified, which does not exclude contemplative praxis, we will refer to the possibility of articulating this concept with happiness in the christian sense.

Key words: Happiness, Aristotle, Páthos, Praxis, Teleology. 


\section{Introducción: la felicidad como bienestar}

La reflexión y el interés contemporáneos sobre la felicidad pueden resultar sorprendentes, pero a poco de recorrer la historia de la filosofía, es posible apreciar una gravitación transversal del asunto, apenas interrumpida en algún período del siglo XX en pleno auge de la tecnociencia. Parecía que la eficacia del mundo tecnológicamente configurado ya no dejaba lugar para pensamientos más próximos a categorías teleológicas que a los imperativos instrumentales inmediatos.

A pesar de eso, últimamente la felicidad ha vuelto a inscribirse hasta como objetivo político explícito, y ya varios países cuentan, incluso, con Viceministerios de la felicidad. Venezuela, por ejemplo, tiene un Viceministerio para la Suprema Felicidad Social del Pueblo, el cual, de acuerdo con la información proporcionada por el propio gobierno, parece más bien centrado en misiones sociales, dirigidas a la atención de sectores en condición de vulnerabilidad. Bután, por su parte, tiene un largo historial en materia de "politización" de la felicidad. En 1972, el rey de ese país, Jigme Singye Wangchuck, creó el concepto de Felicidad Nacional Bruta, el cual debía sustituir al del PIB. A pesar de los problemas de pobreza y desempleo, el cometido actual del ministerio es, según sostuvo el ministro budista del ramo Dasho Karma Tshiteem en una entrevista realizada en Chile en 2012: "que las personas tengan vidas con sentido" (Tshiteem, 2012).

Por su parte, Francia encargó en 2004 a los economistas ganadores del Premio Nobel Joseph Stiglitz y Amartya Sen un sistema de medición del bienestar, que fue posteriormente copiado por el Reino Unido. La OCDE, a su vez, desarrolló un sistema de 11 indicadores (OCDE, 2017). Ya contamos, después de la experiencia pionera de Bután, con diversos estudios en los que se elaboran listas de los países más felices del mundo, entre los que se pueden mencionar el World Happiness Report, encargado por las Naciones Unidas en 2012 y con continuidad (ONU, 2015) y el Happy Planet Index, de la consultora británica New Economics Foundation (Foundation, 2012). También, debemos citar el World Database of Happiness, un completo análisis del profesor holandés de la Erasmus University (Rotterdam), Ruut Veenhoven, que es permanentemente actualizado, (Veenhoven, 2017).

En esta rápida exploración introductoria, llama la atención que en tanto la felicidad es un asunto políticamente relevante, ella se inscribe en un horizonte de significación cercano a un estado de ánimo. No podríamos inferir de esto, sin embargo, que estemos ante un vaciamiento de contenido operado 
contemporáneamente. Ya Aristóteles se hizo cargo de este asunto en un contexto donde, precisamente, la nota dominante de la felicidad era eso, un estado de ánimo, un "bienestar", diríamos hoy. La característica de este estado de ánimo tal como hoy se lo entiende, no difiere demasiado de aquello que Aristóteles analizaba, a no ser en la posibilidad de someterlo a una modelización matemática. Esto último es perfectamente factible gracias a la reapropiación utilitarista del concepto. La fórmula "la mayor felicidad para el mayor número" es ya una clara invitación a esa cuantificación que, por cierto, no tardó en efectuarse como lo prueban los diversos "índices de felicidad" ya aludidos.

Así pues, me propongo analizar la felicidad en la línea inaugurada por Aristóteles, especialmente en lo relativo a la distinción entre la conceptualización pasiva de la misma, entendida como estado de ánimo, y su significación activa, asociada a una cierta manera de obrar, a una praxis. Esta distinción no es excluyente, como intentaré mostrar.

Por cierto, no es éste el lugar para reconstruir una historia de la felicidad, pero sí se podría elaborar un rápido inventario de algunas reflexiones aristotélicas y cristianas sobre la misma, y a partir de allí extraer algunas conclusiones significativas (McMahon, 2006).

\section{La perspectiva clásica: Aristóteles}

Dijo alguna vez Ortega que la claridad es la cortesía del filósofo. En ese sentido, nunca podremos agradecer demasiado los términos en que han llegado hasta nosotros la Ética Nicomáquea y la Política, a pesar de tantas manipulaciones e inverosímilmente desprolijas traducciones. Es muy probable que Aristóteles tuvo de verdad la intención de hacerse entender claramente por los oyentes de sus lecciones acerca de la filosofía de los asuntos humanos, como él mismo llama a sus reflexiones sobre las cosas políticas y sobre sus naturales prolegómenos éticos. Una de las premisas metodológicas de estas obras aristotélicas parece haber sido el intento de postergar todo vocabulario técnico específico de la filosofía y hacerse cargo del reto que implicaba decir cosas importantes sobre la vida humana, empleando solamente los conceptos y palabras al uso en esa misma vida. $Y$ esto sin menoscabo del rigor argumentativo necesario para una verdadera jerarquización científica de sus razonamientos. 
Por cierto, existen términos cuya prosapia filosófica es indiscutible y que presentan, al mismo tiempo, una enorme comodidad para el filósofo profesional. A pesar del hartazgo de Maclntyre por los artículos filosóficos escritos para revistas especializadas, y solamente comprensibles por los iniciados (Maclntyre, 2001), no me parece del todo inconveniente la elaboración de un léxico filosófico específico. Por supuesto, a condición de que éste guarde la cortesía de mantenerse dentro de ciertos límites impuestos por la comunicabilidad misma de las ideas. La preocupación aristotélica entonces parece haber sido la siguiente: ¿cómo decir cosas importantes para la vida con palabras de uso corriente?

Por cierto, una de esas cosas importantes es el asunto del fin de la propia vida. Si esto no se resuelve, o al menos si no se plantea, una filosofía de la vida queda mutilada. ¿Por qué y para qué vivimos? ¿Cuál es, en último análisis, el sentido de nuestra vida? Notemos aquí que, ni por un momento, Aristóteles se detiene a examinar si existe realmente un sentido de vivir; ése es un punto de partida, un principio sobre el cual no se discute. La pregunta que un contemporáneo se siente obligado a hacer es, precisamente, si la vida tiene un sentido. Respecto de esto, tendríamos que parafrasear a Sartre cuando habla de Dios, y decirnos que si la vida no tiene un sentido, deberíamos construirlo. Convengamos con Aristóteles en que el solo hecho de vivir, incluso sin hacerse demasiadas preguntas filosóficas, ya tiene una "cierta dulzura natural", y que esa dulzura natural no está dada solamente por el goce puntual de alguna circunstancia, o por el hecho de no tener un número excesivo de problemas, sino también por el disfrute de nuestros recuerdos y nuestras esperanzas, es decir, de aquellos dos puntos cardinales entre los cuales se va desplegando nuestra existencia:

“(...) quizás en el solo vivir existe cierta dosis de bondad si no hay en la vida un predominio excesivo de penalidades. Es evidente que la mayoría de los hombres soporta muchos padecimientos por afán de vivir, y parecen encontrar en la vida misma cierta felicidad y dulzura natural" (Política, 1278b 28-30).

Para Aristóteles la vida tiene un objetivo último, el cual, sin embargo, como la naturaleza de la que habla Heráclito, ama ocultarse. Esa meta final no está dada de una sola vez y para siempre y tampoco es una sumatoria de momentos agradables. Por el contrario, se trata de algo bastante arduo que exige toda una serie de ejercicios prácticos sobre uno mismo a lo largo de los años. Sería muy conveniente rescatar el concepto de "ejercicio espiritual" en sede filosófica, tal como lo ha propuesto magníficamente Pierre Hadot $(1995 ; 2001)$. 


\section{Un sentido del vivir humano que no es tautológico}

Lo sorprendente de esta filosofía aristotélica es que, a pesar de la importancia de semejante quehacer sobre uno mismo, no se sigue necesariamente que uno deba ser lo más importante para uno mismo. Esto es así porque, según el filósofo, el hombre no es lo mejor que existe en el universo, y si hemos de vivir de un modo auténticamente humano, parece más bien que deberemos hacerlo de una manera no totalmente humana. Leemos en Et. Nic. 1177b 27-35:

"Tal vida (sc. la contemplativa), sin embargo, sería demasiado excelente para el hombre. En cuanto hombre, en efecto, no vivirá de esta manera, sino en cuanto hay en él algo divino, y en la medida en que ese algo es superior al compuesto humano, en esa medida lo es también su actividad a la de las otras virtudes. Si, por tanto, la mente es divina respecto del hombre, también la vida según ella es divina respecto de la vida humana. Pero no hemos de tener, como algunos nos aconsejan, pensamientos humanos puesto que somos hombres, ni mortales puesto que somos mortales sino en la medida de lo posible inmortalizarnos y hacer todo lo que está a nuestro alcance por vivir de acuerdo con lo más excelente que hay en nosotros".

La opinión aristotélica acerca del verdadero puesto del hombre en el cosmos no es, ciertamente, antropocéntrica. Al respecto, es por lo menos llamativo que a una cosmología geocéntrica corresponda una antropología no antropocéntrica y que, en la modernidad, una cosmología no geocéntrica se lleve tan bien con una antropología antropocéntrica. Y si esto es así, resulta claro que el conocimiento exhaustivo de las cosas humanas, en especial de la principal de las cosas humanas, esto es, de la Política, no es el mejor ni el más elevado de los conocimientos ("Sería absurdo considerar la política, o la prudencia, como la más excelente <ciencia> si el hombre no es lo mejor del mundo" <Et. Nic. 1141a 1922>. El fin buscado por la política, en realidad, es algo "superficial" <epipolaíos> respecto del verdadero sentido de la vida: Et. Nic. 1095b 24). Imaginémonos el desagrado que esto debe haber significado si fue dicho en medio de un auditorio de políticos, como probablemente sucedió con estas lecciones de antropología que el Estagirita dictaba (Bodéüs, 1982, pág. 118 ss.). Aristóteles estaba persuadido de que "también hay otras cosas de naturaleza mucho más divina que la del hombre, como es evidentísimo por las que constituyen el mundo", nos dice (Et. Nic. 1141a $34-1141 b$ 1). Hay aquí algunos puntos muy importantes, y el primero de ellos, creo, es la necesidad de rastrear aquel sentido de la existencia con un método que podría llamarse el del descentramiento, y que consiste en la búsqueda de un centro divino en todas las cosas, aun cuando no pueda hablarse de una verdadera participación en la naturaleza divina. 
Si hay un sentido de la vida, y sobre esto no hay duda, parece entonces que ese sentido no es un autosentido, como si dijéramos que el hombre, para Aristóteles, no puede ser nunca un fin en sí mismo. Es más, no parece que nada tenga su último núcleo finalístico en sí mismo, aun cuando las cosas se comporten como recipientes de esa finalidad. Por eso me parece que el descentramiento teleológico es la clave hermenéutica de la teoría de la finalidad en Aristóteles Alejandro Vigo ha señalado una tensión no resuelta en la teoría finalística aristotélica (Vigo, 1994). Por una parte, parece que el fin de una cosa no es exterior a ella misma. Pero por otra, esa cosa se inscribe y tiene su sentido en un vasto sistema teleológico cuyo punto final no es interior a esas cosas. En rigor de verdad, desde una perspectiva clásica y si cupiese hablar de un anacronismo como el de la "dignidad humana" -y digo anacronismo porque no creo que alguna vez haya pasado por la cabeza de un griego hablar de una cosa semejante, esa dignidad no podría fundarse jamás sobre una supuesta condición del hombre como fin en sí mismo (Macklin, 2003). Ciertamente, no pretendo negar la importancia del concepto de "dignidad", pero sí alertar contra un posible uso fraudulento. Esa presencia de lo divino en el hombre es realmente la presencia de algo extraño y desequilibrante que se erige como una barrera infranqueable a todo intento de autofinalidad. En todo caso, es interesante subrayar el hecho de que ninguna de las cosas de este mundo puede explicarse en lo más íntimo que ella tiene por la sola referencia a sí misma. Hace falta un plus, hace falta la presencia de lo divino como dando sentido al universo entero (Metafísica 1075a 10-15).

\section{Una importante corrección estoica y vuelta a Aristóteles}

Quisiera señalar en este punto que la respuesta aristotélica a la pregunta por el sentido de la vida tiene, para un hombre cristiano, algunas limitaciones bastantes serias. Una de las más importantes es que la misma pregunta por el sentido de la vida sólo puede ser efectuada con alguna posibilidad de ser respondida satisfactoriamente, quiero decir, operativamente satisfactoria, por hombres para quienes no solamente los problemas básicos de la vida ya están resueltos, sino también por hombres seriamente encaminados en el hallazgo de ese sentido. Los ejércitos enteros de miserables, tanto en lo económico como en lo social y moral, no tienen, en la filosofía humana de Aristóteles, prácticamente ninguna posibilidad de acceso a lo que el filósofo desea revelar a unos pocos afortunados. La eficacia terapéutica de la filosofía práctica aristotélica es, realmente, muy limitada. Aristóteles ha venido a proporcionar vitaminas a hombres sanos, y no una medicina para los enfermos: 
"In short: if one agrees with Aristotle, then philosophy can do little for the real misery of the world. It can refine already refined and lucky young gentlemen. It can point the way toward an ideal that may or may not have any chance of being realized in any place at any time. These are the limits of its practical efficacity. If, however, one conceives of philosophy as a medical art for the human soul, one is unlikely to accept this as the last word. For medicine would be no good as medicine if it simply gave vitamins to the healthy and designed impracticable schemes for ideal health insurance. Its job is here and now, with the patient's actual suffering. It does nothing for these sufferings. If it does nothing for these sufferings, it does nothing at all" (Nussbaum, 1994, cap. 3, pág. 101).

Pero nuestro problema es que los enfermos son muchos, demasiados, y para ellos ninguna terapia podría hallarse en la filosofía aristotélica: "Para tales personas, el conocimiento <de la filosofía moral> resulta inútil, como para los intemperantes; en cambio, para los que encauzan sus deseos y acciones según la razón, el saber acerca de estas cosas será muy provechoso" (Et. Nic. 1095a 9-12 ; cfr. Id. 1099a 31 ss ; Pol. 1331b 38-1332a2: "es evidente que todos aspiran a vivir bien y a la felicidad, pero unos tienen la posibilidad de alcanzarlo y otros no, por un fallo de la naturaleza o de la fortuna (porque el vivir bien requiere una cierta medida de bienes de fortuna, menor para los que están en mejor posición y mayor para los que están en posición inferior), y otros empiezan por no buscar rectamente la felicidad, aunque disponen de los recursos necesarios"). Este parece haber sido el escollo insalvable de esta filosofía advertido ya por los estoicos (Nussbaum, 1994, cap. 3). La respuesta política contemporánea a esta exclusión, considerando incluso la necesidad de reconstituir el vínculo entre ética y política, ha consistido, no en una integración de los marginales al selecto grupo de quienes acceden a los goces divinos de la contemplación metafísica, sino más bien en una completa desestimación de esta última bajo la grave acusación de fantasiosa. Lo que el hombre contemporáneo quiere es ser él mismo el centro y el fundamento de toda antropología y, por lo tanto, de toda ética y de toda política. La respuesta política moderna a las limitaciones de la ética aristotélica es el utilitarismo. La filosofía política que el mundo de hoy desea es el utilitarismo, con todos los refinamientos que se quiera, pero utilitarismo en último análisis. Éste presenta el enorme atractivo de permitir definir la moralidad de las acciones en función de la respuesta que se dé a la pregunta: esto que yo hago, ¿a quién perjudica o favorece?, como bien lo ha señalado Will Kymlicka (Kymlicka, 1995) (Marías, 2008; 9a reimpresión).

De todos modos, propongo hacernos cargo por el momento del hecho de que los eventuales lectores de estas líneas (y de quien las escribe, naturalmente), 
podrían merecer las revelaciones de Aristóteles porque nuestros problemas básicos, tanto económicos como morales, ya están más o menos solucionados. La doctrina aristotélica es, en todo caso, elitista, pero no por eso necesariamente falsa.

Así pues, ¿qué nos dice Aristóteles del sentido de la vida? Que éste es la felicidad. Paso por alto ahora el modo sencillo e impecable como Aristóteles llega a esta conclusión, por ser un asunto suficientemente conocido por los eventuales lectores de estas líneas. Tratemos ahora de reflexionar más bien acerca del contenido de esta felicidad. Así entonces, si la felicidad es un fin, la búsqueda teórica de su contenido material viene en cierta medida facilitada por el hecho de que la misma naturaleza humana lo señala más allá de toda deliberación. El fin es "puesto" por la naturaleza. A nosotros se nos deja un trabajo en cierto modo más sencillo, en cierto modo más difícil. Más sencillo, porque no tenemos que ocuparnos de decidir acerca de cuál pueda ser ese fin de lo humano, o ese sentido de la vida (Et. Nic. 1112b 11: "no deliberamos sobre los fines sino sobre las cosas que conducen a los fines"). Ésta es una decisión que ya ha sido tomada por algo 0 alguien que no somos nosotros; es la decisión que se manifiesta, por ejemplo, en el objetivo final al cual apunta la virtud. Y en cierto modo es más difícil, porque tenemos la obligación de decidir acerca del camino que nos conducirá hacia ese fin.

\section{La vita contemplativa y sus dificultades}

Ahora bien, si el contenido material de esa felicidad es la vida contemplativa, esto es, la contemplación de aquellos entes cuya naturaleza es superior a la humana, está claro que el ejercicio de esa contemplación implica un acto de visión, y como tal, se trata de un ejercicio teórico. Y si la felicidad se identifica con un acto de la inteligencia, ¿por qué habríamos de suponer que ese acto debe estar precedido por un gobierno de nuestras emociones y nuestros deseos, tal como lo exige la virtud moral? En una palabra, ¿por qué Aristóteles defiende la superioridad de la contemplación en el marco teórico de la Ética Nicomáquea y no en los Segundos Analíticos, por ejemplo? La objeción de un matemático podría ser que él puede perfectamente ejercitar su razón teórica sobre cosas cuya naturaleza es superior a la humana, y ser, por lo tanto, un buen candidato a la felicidad. Pues bien, la verdadera pregunta aristotélica es más bien la siguiente: ¿existe alguna cosa superior al hombre cuya contemplación tenga una directa relación con el tipo de persona que uno debiera ser? ¿Por qué y cómo la visión de ciertas cosas 
puede afectar incluso la misma vida moral de quien ejercita la contemplación, por ejemplo?

Creo que tocamos aquí uno de los puntos más provocativos de la teoría de la felicidad aristotélica, y es el siguiente: la contemplación de lo divino, como contenido material de la felicidad, es tan profunda y arrebatadora que no puede quedar aprisionada en los moldes de lo que hoy llamamos "ciencia". Uno puede dedicarse a una ciencia, a la filosofía, incluso. Pero lo que el Estagirita plantea es que esa dedicación debe configurarse de tal modo que constituya, nada más y nada menos, que toda una vida, la vida contemplativa. La contemplación a la que se refiere Aristóteles no es tanto el producto científico de la misma, sino la misma vida consagrada a la contemplación. La vida contemplativa es abordada por Aristóteles, no ya desde el punto de vista del resultado exterior diríamos, sino en tanto actividad (praxis), pues la actividad es superior a la inacción (apraxía) (Pol. 1325a 31). Así entonces, si la felicidad ha sido definida como una cierta praxis (Física 197b 5: "la felicidad es cierta clase de acción, la buena acción"), una cierta acción antes que una inacción, esto no implica que esa acción en que consiste la felicidad deba ser necesariamente una acción que "se refiera a otros, como algunos piensan, ni el pensamiento es práctico únicamente cuando se ejercita en vista de los resultados que se obtienen de la actuación, sino que lo son mucho más la contemplación y la meditación que tienen su fin en sí mismas y se ejercitan por sí mismas" (Pol. 1325b 16-20 -itálicas mías-). En una palabra, hay una praxis suprema que no es política; esa praxis suprema es la contemplación. Desde esta perspectiva, se acorta mucho la distancia entre el ejercicio de la ciencia y la vida moral; es más, la definición de la ciencia comparte con la definición de la vida moral una base conceptual común: el hábito (héxis). La ciencia no es, primordialmente, aunque sí lo sea de algún modo, una realidad objetiva, exterior, almacenada en libros, o un resultado; ella es, antes que nada, un hábito interior del científico, y de este carácter habitual depende su íntima conexión con el plano de la moralidad, pues para que haya hábito tiene que haber antes una decisión, una prohaíresis. Y a su vez, la ciencia suprema, la filosofía, es la ciencia de la verdad ("Es justo que la filosofía sea llamada ciencia de la verdad": Metafísica, 993b 20), es decir, el otro concepto que sirve de conexión entre las esferas de lo teórico y lo práctico. Y todas estas cosas Aristóteles las dice en la Política, esto es, en el contexto de la más importante de las ciencias prácticas. Así entonces, si la felicidad es una cierta praxis, corresponde a la política ocuparse de la felicidad, pues la política es la ciencia de la praxis. Y si esta praxis en que consiste la felicidad es la vida contemplativa, la política también está quebrada en su interior por aquel descentramiento finalístico, pues el fin que ella sirve, no es, en última 
instancia, un fin político. Así entonces, una de las más importantes lecciones de la política aristotélica, o sea, de ese saber que se ocupa nada menos que del fin último de nuestra existencia, es la desabsolutización de lo político. La verdadera felicidad no coincide con los fines inmediatos de la política. El ciudadano que alcanza a ver esto, ya está un escalón por encima de sus conciudadanos y sobre todo de los sofistas (Et. Nic. 1177b 30-35).

En la versión aristotélica de la felicidad sería preferible conservar lo que ella tiene de salida de uno mismo, antes que identificarla con el ejercicio de la vida contemplativa. John Finnis, por ejemplo, ha subrayado esto que él mismo llama un "bloque errático" en el argumento aristotélico, y que consistiría en pensar que "porque un aspecto de la naturaleza humana no es compartido por otras creaturas, éste debe ser el más elevado, o incluso el exclusivo objeto del interés humano" (Finnis, 1985, pág. 122). También escribe Finnis, op. cit., p. 15:

"(...) we should not suppose that the most important characteristics of humanity are to be identified by identifying those that distinguish us from all other kinds of being. For one thing, the argument would lead to a conclusion which Aristotle does not want; for he wants all his arguments to support the view that the ultimate telos of man is theoretical contemplation; but contemplation is not peculiar to human beings; it is a characteristic which, on Aristotle's own account, we share with the gods".

Uno de los pasajes decisivos del Estagirita, que parece confirmar la tesis de Finnis, lo tenemos en Et. Nic., X, 7, 1177a 12 ss:

"Si la felicidad es una actividad conforme a la virtud, es razonable que sea conforme a la virtud más excelente, y ésta será la virtud de lo mejor que hay en el hombre. Sea pues el entendimiento (noûs) o se alguna otra cosa lo que por naturaleza parece mandar y dirigir y poseer intelección de las cosas bellas y divinas, siendo divino ello mismo o lo más divino que hay en nosotros, su actividad de acuerdo con la virtud que le es propia será la felicidad perfecta (teléia eudaimonía). Que es una actividad contemplativa (theoretiké), ya lo hemos dicho".

No se puede evitar cierta insatisfacción frente a la presentación de la felicidad humana como el solo ejercicio de la vida contemplativa. Aristóteles no se priva de defenderla, incluso como una actividad solitaria (Eth Nic. X, 7, 1177a 33: "...el sabio, aun estando solo, puede practicar la contemplación, y cuanto más sabio sea, más aún"). Todas aquellas actividades que involucran a otro, por más respetables que sean, tendrán siempre un dejo de superficialidad, término empleado por el 
mismo filósofo. En el pasaje de Et. Nic., I, 5, 1095b 24, Aristóteles se refiere nada menos que al bíos politikós, esto es, al tipo de vida más elevado al que puede acceder la acción humana. Esta manera de vivir queda claramente relegada al segundo puesto (deutéros: $X, 8,1178$ a 9) entre los modos posibles que un hombre puede elegir en libertad, comparados con la contemplación. De hecho, una de las tesis de Hannah Arendt en The Human Condition es que este enorme prestigio de la vida contemplativa operó el eclipse de las distinciones en el interior de la vita activa, esto es, las diferencias entre la actividad del trabajo, de la obra y de la acción, que fueron inventariadas en una sola categoría: la vita activa.

Por cierto, no se podría introducir un hiato insalvable entre una manera de vivir superior, la vida contemplativa, y otra inferior, la vida de las virtudes del carácter, pues todo parece indicar el valor propedéutico de las segundas respecto de la primera, la cual incluso tiene una carga teleológica para ellas. De todos modos, el texto aristotélico no brinda mayores precisiones acerca del modo de relación entre ambas. No deja incluso de verse cierto pesar por parte del filósofo en cuanto al necesario involucramiento en materias políticas, pues en esto consiste su reaseguro para el ejercicio de la vida superior. Diríamos, con Alejandro Vigo, que hay más bien razones fácticas para la armonización entre vida contemplativa y vida activa, antes que razones de derecho:

"El requerimiento que lleva al filósofo a volver a la caverna, esto es, a intervenir en la actividad práctico-política en el marco de la comunidad es, pues, un requerimiento de índole fáctica o, dicho de otro modo, una exigencia impuesta por las condiciones fácticas de la existencia humana" (Vigo, 2003).

Hay aquí otra evidente tensión no resuelta en el esquema aristotélico relativo a la felicidad: si ésta consiste en la vida contemplativa, a saber, una vida solitaria, ¿cómo es posible defender al mismo tiempo una "salida de sí mismo"? ¿Acaso no hubiera sido más coherente esperar razones que nos expliquen que la felicidad también tiene que ver con la generosidad, la negación de uno mismo y las obligaciones con los demás? Al respecto, escribe Vigo, p. 104 de la obra antes citada:

"Nosotros esperaríamos, además, que se nos den razones basadas en el altruismo y la caridad para con el otro, el olvido de sí mismo y los deberes para con los demás. Nada de esto, por cierto, aparece en esta forma en Aristóteles 0, por lo menos, no ocupa nunca el primer plano de su reflexión moral. Ante esta constatación, la tentación inmediata es la de ver en la concepción de Aristóteles una variante de la ética del egoísmo (...)". 


\section{Conclusión: de la felicidad como sentimiento a la felicidad como acción}

De esta descripción podemos concluir, entre otras cosas, que la felicidad no es, primariamente un "estado", ni una "emoción", tal como acertadamente lo recuerda Darrin McMahon:

"Many of us today would probably be quick to describe happiness in that way -as a good feeling or positive mood. Yet the very first taxonomist of the emotions, Aristotle, excluded happiness from his classifications, The list of emotions he provides in the Rhetoric, the most complete of several such accounts, includes anger, love, enmity, fear, pity, indignation, envy and contempt. But 'happiness' (eudaimonia), is apparently something else" (McMahon, 1976, p. 62).

A pesar de ello, el mismo Aristóteles asume como punto de partida el mismo concepto de eudaimonía, de uso corriente entre los griegos del siglo IV a.C., para designar la felicidad. He tratado de mostrar el modo empleado por el Estagirita para avanzar un paso importante más allá del uso vulgar, tal vez demasiado cercano a la felicidad como emoción, enfatizando la relación que ella debe tener con la virtud (Abbà, 1992). No obstante, el mismo filósofo no deja de reconocer la proximidad conceptual entre la felicidad y otros términos que generalmente están asociados con la buena fortuna, esto es, con cosas que no dependen de uno. Un hombre con "suerte" (eutyches), "favorecido" (olbios) y "bienaventurado" (makarios) es un hombre que no puede no ser feliz, aun cuando esa felicidad parece no depender de él, sino del favor de los dioses. Después de todo, el hombre feliz (eu-daimon) es el hombre de "buen-humor" (pero no entendido como se lo entiende en la acepción corriente en español, donde no distinguimos, por ejemplo humour de humeur como en francés). El hombre feliz, el eu-daimon, es el hombre "contento" en su doble significación, la habitual y la que significa "contenido", "satisfecho". En todo caso, la acepción corriente para describir al hombre eu-daimon, tiene una fuerte carga semántica de "buena fortuna".

\section{McMahon señala:}

"In some ways encompassing the meaning of all of these terms, eudaimon (happy) literally signifies 'good spirit' or 'good god', from eu = good and daimon = demon/spirit. In colloquial terms, to be eudaimon was to be lucky, for in a world fraught with constant upheaval, uncertainty, and privation, to have a good spirit working on one's behalf was the ultimate mark of good fortune. Even more it was a mark of divine favor, for the gods, it was believed, worked through daimones, emissaries and conductors of their will' (McMahon, 2004, p. 7). 
La misma palabra "felicidad", si atendemos a una definición nominal, tiene en varias lenguas europeas una connotación próxima a la (buena) suerte. Happines, en inglés se enraíza en happ, que significa "suerte", "fortuna", lo que sucede (happens). Glück, en alemán tiene una raíz semejante: gelingen (tener éxito). La vieja palabra francesa heur (suerte, fortuna) es la raíz de bonheur ("buena fortuna", "felicidad") y de heureux ("afortunado", "feliz"). Felicidad, felicidade, felicità derivan del latín felix ("fortuna", y a veces "destino").

Esta pertinacia ancestral de las lenguas no es nueva; precisamente, la innovación aristotélica consiste en desplazar la espontaneidad lingüística que asocia la felicidad con un estado emocional que, sencillamente, se disfruta, hacia una noción de la felicidad donde la nota distintiva sean la trabajosa voluntariedad y la virtud, que buscan amaestrar los embates de la fortuna. Esto explica, entre otras cosas, la cuidadosa referencia al placer en la Ética a Nicómaco, y su permanente preocupación por relacionarlo con la ejecución de nobles acciones voluntarias:

"Tratándose de cosas de esta naturaleza (sc. los placeres), la impresión verdadera es la del hombre bueno (tô spoudaio); y si esto es cierto, como parece, y la virtud y el hombre bueno en tanto que bueno son medida de cada cosa, serán placeres los que se lo parezcan a él, y agradable aquello en que él se deleite" (Eth. Nic., X, 5, 1176a 16-20).

Aristóteles no es indiferente, de todos modos, a la importancia de los factores externos que concurren en la felicidad. Después de todo, tanto la multitud como los hombres refinados piensan que la felicidad implica tanto un vivir bien (eû zên) como un "irle bien a uno" (eû práttein: Et. Nic. I, 4, 1095a 19). El segundo miembro de esta díada semántica no ofrece mayores dificultades para nadie. Una felicidad completa requiere también de muchas cosas que no dependen de nosotros, y cuya carencia empaña la ventura: nobleza de linaje, buenos hijos y buena apariencia personal por ejemplo (Eth. Nic. I, 8 1099b 2 ss: "No podría ser feliz del todo aquel cuyo aspecto fuera completamente repulsivo, o mal nacido, o solo y sin hijos, y quizá menos aún aquel cuyos hijos o amigos fueran absolutamente depravados, o siendo buenos, hubiesen muerto. Por consiguiente, como dijimos, la felicidad parece necesitar también de esta clase de prosperidad <euemerías>, y por eso algunos identifican la buena fortuna <eutychía con la felicidad; pero otros con la virtud". En realidad, los problemas están en el primero de los miembros, el del vivir bien, por dos razones: una, la felicidad implicaría ya una actividad y no solamente una actitud pasiva; la otra, es la necesidad de decidir en qué consiste esa actividad. En qué tipo de actividad consiste la felicidad y el tipo de dificultades que ello acarrea, ya lo he considerado. 
Señalo ahora un aspecto interesante cuando el Estagirita habla de la felicidad como un don de los dioses al hombre:

"Pues si alguna otra cosa es un don de los dioses a los hombres, es razonable que también lo sea la felicidad, y tanto más cuanto que es la mejor de las cosas humanas (Et. Nic., I, 9, 1099b 11-13)".

Aristóteles vuelve a conectar la felicidad como un asunto íntimamente relacionado con la actividad de los dioses en el final de la Ética Nicomáquea $(X$, 8, 1178b26-28): "La vida de los dioses es toda feliz; la de los hombres, lo es en la medida en que tienen cierta semejanza de la actividad divina".

En este caso, ya no emplea el término eudaimon, sino el de makarios, que los latinos traducen como felix y beatus respectivamente. Si dejamos por un momento de lado la crucial distinción al interior de la felicidad como estado de ánimo y como actividad, tenemos que ella tiene una fuerte conexión con el orden de lo divino que no ha dejado de ser enfatizada por los pensadores cristianos, especialmente por Tomás de Aquino (Summa Theol. la-Ilae, qq.1-5; Cont. Gent. II, xxvi-xl). Pero si volvemos a la distinción entre el estado de ánimo y la actividad asociada a él, veremos rápidamente dónde opera la separación material entre la concepción aristotélica y la cristiana de la felicidad.

En este último punto, se abre la perspectiva de las beatitudes cristianas, impensable y muy probablemente inaceptable para Aristóteles. Allí también se trata de un don de Dios -más precisamente, de los dioses- a los hombres, pero el tipo de praxis es toto coelo diferente toda vez que hay una especial atención a los sufrimientos humanos. ¿Por qué serían felices (makáriol) los que tienen espíritu de pobres, es decir, los que ponen su confianza en Dios antes que en los bienes mundanos, los que sufren, los humildes, los que padecen injusticia, los compasivos, los de corazón limpio, los que trabajan por la paz, los perseguidos por obrar lo justo, los insultados y maltratados por causa de Cristo? (Mat. 5: 3-11. Cfr: Luc. 6: 20-22).

En la comparación de estas dos perspectivas y especialmente en las conclusiones derivadas, puede operarse una fructífera reapropiación de lo esencial de la felicidad después de Aristóteles. En último análisis, la felicidad es, sí, un sentimiento; pero también está necesariamente asociada a un tipo de obrar, que no necesariamente concluye en el ejercicio contemplativo como su última perfección si nos atenemos al testimonio cristiano. 


\section{REFERENCIAS BIBLIOGRÁFICAS}

ABBÀ, G. (1992). Felicidad, vida buena y virtud. Barcelona: Ediciones Internacionales Universitarias S.A.

BODÉÜS, R. (1982). Le philosophe et la cité. París: Les Belles Lettres.

FINNIS, J. (1985). Fundamentals of Ethics. Oxford: Clarendon Press.

FOUNDATION, N. E. (2012). Obtenido de http://www.neweconomics.org/ publications/entry/happy-planet-index-2012-report

HADOT, P. (1995). Philosophy as a Way of Life. Spiritual Exercices from Socrates to Foucault. Edited with an Introduction by Arnold I. Davidson. USA: Blackwell Publishers.

HADOT, P. (2001). La philosophie comme manière de vivre. Entretiens avec Jeannie Carlier et Arnold I. Davidson. París: Albin Michel.

KYMLICKA, W. (1995). Filosofía política contemporánea. Una introducción (cap. 2). Barcelona: Ariel.

MACINTYRE, A. (2001). The Two Faces of Philosophy. Yearbook of the Irish Philosophical Society, 114-126.

MACKLIN, R. (2003). Dignity is a useless Concept: It means no more that Respect for Persons or their Autonomy. Bristish Medical Journal, 1419-1420.

MARÍAS, J. (2008; 9a reimpresión). La felicidad humana, cap. 11: "La cuantificación de la felicidad: el utilitarismo. Madrid: Alianza Editorial.

MCMAHON, D. (1976, Vol. 29, №1). The quest for happiness. The Wilson Quarterly.

MCMAHON, D. (2004, Vol 133, №2). From the Happiness of Virtue to the Virtue of Happiness: 400 B.C. - AD 1780. Daedalus.

MCMAHON, D. (2006). Una historia de la felicidad. Madrid: Taurus. 
NUSSBAUM, M. (1994). The Therapy of Desire. Theory and Practice in Hellenistic Ethics. Princeton: Princeton University Press.

OCDE. (2017). Crea tu propio índice para una vida mejor. Obtenido de http://www. oecdbetterlifeindex.org/es/

ONU. (2015). Obtenido de http://worldhappiness.report/wp-content/uploads/ sites/2/2015/04/WHR-2015-summary_final-ES.pdf

TSHITEEM, D.K. (12 de julio de 2012). De aquí y de allá: Dasho Karma Tshiteem, Ministro de la Felicidad de Bután: "Nos interesa que las personas tengan vidas con sentido". (C. J. Meza, Entrevistador). Obtenido de http://www.revistasomos. cl/2012/09/de-aqui-y-alla-ministro-de-la-felicidad-de-butan-dasho-karmatshiteem-nos-interesa-que-las-personas-tengan-vidas-con-sentido/

VEENHOVEN. (2017). Obtenido de http://worlddatabaseofhappiness.eur.nl/

VIGO, A. (1994). Naturaleza y finalidad. Algunas consideraciones a partir del modelo aristotélico. En A. y. García Marqués, Razón y Práxis (págs. 41-54). Valparaíso: Ediciones de la Universidad de Valparaíso.

VIGO, A. (2003). La concepción aristotélica de la felicidad. Una lectura de Ética a Nicómaco I y X 6-9. Santiago de Chile: Universidad de Los Andes. 